09-11 July 2021

Paris, France

\title{
Study on Recovery, Accumulation and Reuse of Kinetic Energy When Going downhill to Support the Departure and Upward Movement of Small-Sized Timber Tractor complexes
}

\author{
Mai Hoang Long \\ University/Institute: Vinh Long University of Technology Education
}

\begin{abstract}
Cyclic movement in the timber transport technology on sloping land provides the ability to equip the hydraulic system with controlling anchors. The paper introduces some initial research results on the ability and efficiency of recovering and reusing kinetic energy of tractor complexes in the timber transport cycles. Controlling the position of the distribution valves appropriately, which can facilitate the start of the upward movement due to the accumulated energy when the tractor complexes is fully loaded down the slope. Additionally, the accumulated energy can also be used to unload wood at the foot of a slope or to support the loading and unloading of wood when stopping on the slope.
\end{abstract}

Keywords: reusing kinetic energy, accumulated energy, hydraulic system 